\title{
Article \\ Contact Geometry Modification of Friction-Welded Semi-Finished Products to Improve the Bonding of Hybrid Components
}

\author{
Bernd-Arno Behrens ${ }^{1}$, Johanna Uhe ${ }^{1}{ }^{\mathbb{D}}$, Tom Petersen ${ }^{1}$, Florian Nürnberger ${ }^{2}{ }^{\mathbb{D}}$, Christoph Kahra ${ }^{2}$, Ingo Ross ${ }^{1}$ \\ and René Laeger ${ }^{1, *}$ \\ 1 Institute of Forming Technology and Machines, Leibniz Universität Hannover, 30823 Garbsen, Germany; \\ behrens@ifum.uni-hannover.de (B.-A.B.); uhe@ifum.uni-hannover.de (J.U.); \\ petersen@ifum.uni-hannover.de (T.P.); ross@ifum.uni-hannover.de (I.R.) \\ 2 Institute of Materials Science, Leibniz Universität Hannover, 30823 Garbsen, Germany; \\ nuernberger@iw.uni-hannover.de (F.N.); kahra@iw.uni-hannover.de (C.K.) \\ * Correspondence: laeger@ifum.uni-hannover.de; Tel.: +49-5117624958
}

Citation: Behrens, B.-A.; Uhe, J.;

Petersen, T.; Nürnberger, F.; Kahra, C.; Ross, I.; Laeger, R. Contact Geometry Modification of Friction-Welded Semi-Finished Products to Improve the Bonding of Hybrid Components. Metals 2021, 11, 115. https:// 1doi.org/0.3390/met11010115

Received: 17 November 2020

Accepted: 4 January 2021

Published: 8 January 2021

Publisher's Note: MDPI stays neutral with regard to jurisdictional clai$\mathrm{ms}$ in published maps and institutional affiliations.

Copyright: $\odot 2021$ by the authors. Licensee MDPI, Basel, Switzerland. This article is an open access article distributed under the terms and conditions of the Creative Commons Attribution (CC BY) license (https:// creativecommons.org/licenses/by/ $4.0 /)$.

\begin{abstract}
To improve the bond strength of hybrid components when joined by friction welding, specimens with various front end surface geometries were evaluated. Rods made of aluminum AA6082 (AlSi1MgMn/EN AW-6082) and the case-hardening steel 20MnCr5 (AISI 5120) with adapted joining surface geometries were investigated to create both a form-locked and material-bonded joint. Eight different geometries were selected and tested. Subsequently, the joined components were metallographically examined to analyze the bonding and the resulting microstructures. The mechanical properties were tested by means of tensile tests and hardness measurements. Three geometrical variants with different locking types were identified as the most promising for further processing in a forming process chain due to the observed material bond and tensile strengths above $220 \mathrm{MPa}$. The hardness tests revealed an increase in the steel's hardness and a softening of the aluminum near the transition area. Apparent intermetallic phases in the joining zone were analyzed by scanning electron microscopy (SEM) and an accumulation of silicon in the joining zone was detected by energy-dispersive X-ray spectroscopy (EDS).
\end{abstract}

Keywords: friction welding; hybrid components; tailored forming; surface geometry modification

\section{Introduction}

If a component has to withstand diverse local loads or a lightweight design is demanded [1], the combination of different materials offers the use of a load-adapted component. Components consisting of at least two materials are called hybrid components. Due to different material-specific properties such as melting points or flow stresses, these components require adapted joining methods. Depending on the specific material combination, this can be, for example, a fusion welding process or a friction welding process.

The most important technical advantages of friction welding compared to fusion welding are the high reproducibility and the wide variety of possible material combinations, such as aluminum and steel, since the joining process is based on plastic deformation instead of melting. Compared to friction welding, fusion-welded products have much larger heat-affected zones which can result in undesired microstructures and reduces the resilience of parts [2]. The molten phase may cause defects such as gas porosity, which leads to brittle fracture.

Common multimaterial components are produced by joining several individual parts that are already in a near-net shape. Therefore, the joining process takes place at the end of the process chain-for example, splicing or riveting of sheet metal components in the production of automobile chassis [3]. Another approach is joining by forming, such as the consolidation of powder with simultaneous bonding with steel during forming to produce 
hybrid gears [4] or the application of ultrasound enhanced friction stir welding to join different materials [5].

As part of the collaborative research center 1153 (CRC 1153) "Tailored Forming", a novel process chain was developed, in which various materials are joined at an initial stage before being subjected to further processing [6]. The aim of this concept is to further improve the joining zone by the subsequent processing steps resulting in a load-adapted component. The CRC 1153 maps several process chains in their entirety, to improve components such as shafts, bevel gears or bearing disks [6]. The process chain for manufacturing hybrid shafts by applying friction welding is depicted in Figure 1. Within this process chain, joining is followed by impact extrusion, which requires a homogenous formability in both material sections. Hence, an inhomogeneous temperature distribution in the joined parts prior to the forming has to be ensured to align the flow curves of the investigated $20 \mathrm{MnCr} 5$ steel and of the AA6082 aluminum alloy (EN AW-6082). Therefore, a customized inductive heating strategy was developed to achieve the material-specific forming temperatures of $900{ }^{\circ} \mathrm{C}$ in steel and $20^{\circ} \mathrm{C}$ in aluminum simultaneously [7].

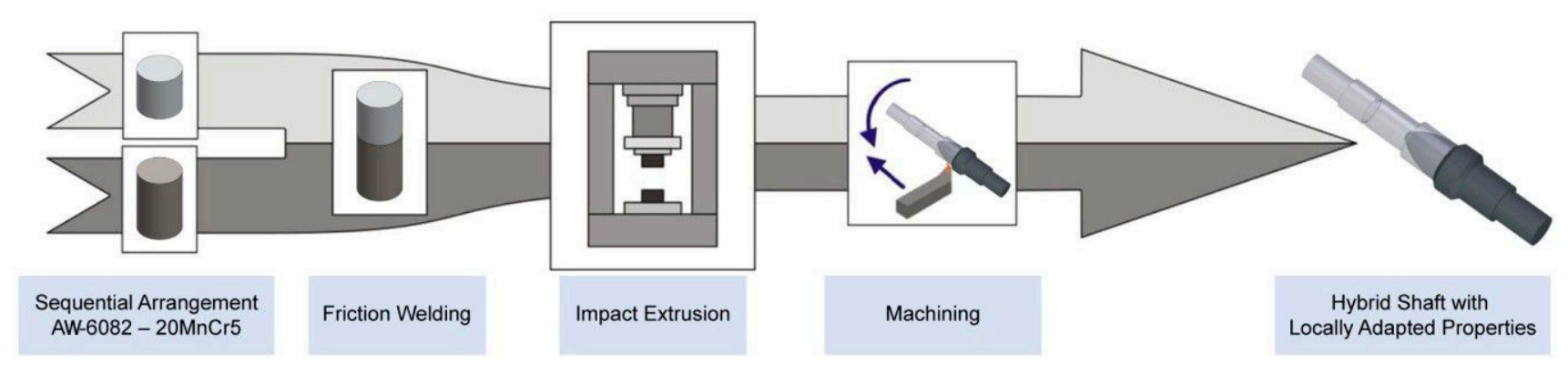

Figure 1. Schematic tailored forming-process chain of the collaborative research center 1153 (CRC 1153) [8], material combination EN AW-6082 (AA6082) and 20MnCr5.

Friction welding was selected based on various reports which concluded that the successful joining of aluminum alloys and steels and the free designability of joining zone geometry-e.g., Ashfaq et al. detected an increased bond strength when using a conical geometry instead of flat surface. They found that this modification benefits material flow and results in an improved bond quality [9]. Fukumoto et al. investigated the influence of different parameters on the completeness of the bond. The most significant result was that the highest bond strength is achieved by certain friction times of $1 \mathrm{~s}$ with a pressure of $50 \mathrm{MPa}$ and $6 \mathrm{~s}$ with a pressure of $150 \mathrm{MPa}$. Higher or lower friction times resulted in lower bond strength [10]. Lee et al. focused on the resulting microstructures and their correlations with the friction parameters. Besides the base metals, they identified different regions - that is, a region of dynamic recrystallization-a heat-affected zone (HAZ) and a deformation zone, and how these are formed due to different forming pressures (70 to $150 \mathrm{MPa}$ ) and friction times (0.1 to $3.0 \mathrm{~s})$ [11]. Fukumoto et al. studied the properties of the bonds created by a friction welding process of the aluminum alloy EN AW 1050 and the stainless steel 1.4301 (AISI 304). They were able to show that the extension of the frictional time from 0.1 to $0.2 \mathrm{~s}$ increased the bond strength from 85 to $96 \mathrm{MPa}$ [12]. Sahin characterized the bond by different test methods such as tensile tests and hardness measurements and found a significant influence of contaminants at the interface on the joint quality. He recommended a statistical analysis as an economical and reliable method for selecting optimized welding parameters [13]. Behrens et al. investigated the influence of surface geometry by using a conical shape. They found out that at room temperature a sharper shape with an increased friction path results in a higher bond strength. Compared to specimens with flat surfaces, bond strength could be improved from 252 to $294 \mathrm{MPa}$ using a conical surface of $30^{\circ}$ [14]. So far, only a few studies such as [9], [14] or [15] took an adaption of the surface geometry into account. In [15], the effects of frictional contact surfaces on the formation of an intermetallic phase were studied. Since most investigations 
are focused on flat surfaces, which often show compound defects in the zone around the central axis after joining [10], on other material combinations or without focusing the bonding strength [15], further research is required regarding alternatives such as a combination of material bond and form locking by varying the friction contact geometries. Comparison these results with additional references is only possible to a limited extent, since parameters of the friction welding process differ as well as the material combinations.

Friction welding processes are divided into three sequences: contact phase, friction phase and deformation phase [16]. In the contact phase, the geometries are aligned and brought into contact with a specific pressure. The heat is generated in the friction phase, in which one component begins to rotate-in this case, the steel side. This phase can be adjusted by controlling the friction time or the relative friction path of the welding components covering in the axial direction. In the deformation phase, the rotation stops and the welding components are joined by generating high axial pressure.

To improve the bonding strength of the steel-aluminum specimen and thus manufacture semifinished parts suited to subsequent impact forging, this work is mainly concerned with varying the contact geometries. In addition to increasing the contact areas between both materials or increasing the contact times and contact pressures in the sample center, possibilities for generating a form closure are also investigated in addition to the pure material bond. Different combinations of friction surface geometries are tested experimentally in the following and their impact on the bond strength is determined. For example, the applicability of undercuts is examined to implement the additional bonding mechanisms such as form locking.

\section{Materials and Methods}

The following subsections describe the applied materials and the performed methods of the investigation. For this purpose, the basic conditions are explained and clarified with the help of illustrations.

\subsection{Materials}

For the friction welding, the aluminum alloy AA6082 (EN AW-6082) and the case hardening steel $20 \mathrm{MnCr} 5$ were chosen. $20 \mathrm{MnCr} 5$ is a chromium-manganese alloyed steel. During friction welding, the steel was employed in its delivery condition (soft annealed) with a tensile strength of $554 \mathrm{MPa}$. The aluminum alloy used featured the T6 condition with a tensile strength above $360 \mathrm{MPa}$. The mechanical properties, tested in prior investigations, are listed in Table 1 and the chemical compositions are given in the content lists in Table 2, measured by optical emission spectrometry.

Table 1. Mechanical properties of the $20 \mathrm{MnCr} 5$ steel and AA6082 aluminum alloy.

\begin{tabular}{ccccc}
\hline Material & $\begin{array}{c}\text { Tensile Strength } \\
\mathbf{R}_{\mathbf{m}} \text { in } \mathbf{M P a}\end{array}$ & $\begin{array}{c}\text { Uniform } \\
\text { Elongation } \mathbf{A}_{\mathbf{g}} \text { in } \%\end{array}$ & $\begin{array}{c}\text { Elongation at } \\
\text { Fracture A in } \%\end{array}$ & $\begin{array}{c}\text { Hardness in } \\
\text { HV0.1 }\end{array}$ \\
\hline 20MnCr5 & $554 \pm 5$ & $111 \pm 1$ & $276 \pm 6$ & $170 \pm 13$ \\
AA6082 & $364 \pm 0$ & $45 \pm 1$ & $104 \pm 6$ & $113 \pm 1$ \\
\hline
\end{tabular}

Table 2. Chemical composition of the $20 \mathrm{MnCr} 5$ steel and AA6082 aluminum alloy in wt.\%., measured by optical emission spectrometry.

\begin{tabular}{ccccccccccccc}
\hline Element & $\mathbf{C}$ & $\mathbf{S i}$ & $\mathbf{M n}$ & $\mathbf{P}$ & $\mathbf{C r}$ & $\mathbf{S}$ & Al & Fe & $\mathbf{C u}$ & $\mathbf{M g}$ & $\mathbf{Z n}$ & $\mathbf{T i}$ \\
\hline 20MnCr5 & 0.195 & 0.275 & 1.190 & 0.013 & 1.050 & 0.010 & 0.030 & 96.85 & 0.164 & - & 0.023 & - \\
AA6082 & - & 1.040 & 0.451 & 0.001 & 0.035 & - & 97.60 & 0.152 & 0.031 & 0.620 & 0.011 & 0.018 \\
\hline
\end{tabular}

The microstructures of both base materials prior to friction welding are shown in Figure 2. On the left side (a) the ferritic-pearlitic microstructure of the steel $20 \mathrm{MnCr} 5$ is depicted. To visualize the grain boundaries and the different microstructures, the sample 
was etched with Nital, a solution of nitric acid (3\%) and alcohol. A micrograph of the aluminum alloy in its T6 condition is shown on the right side (b).
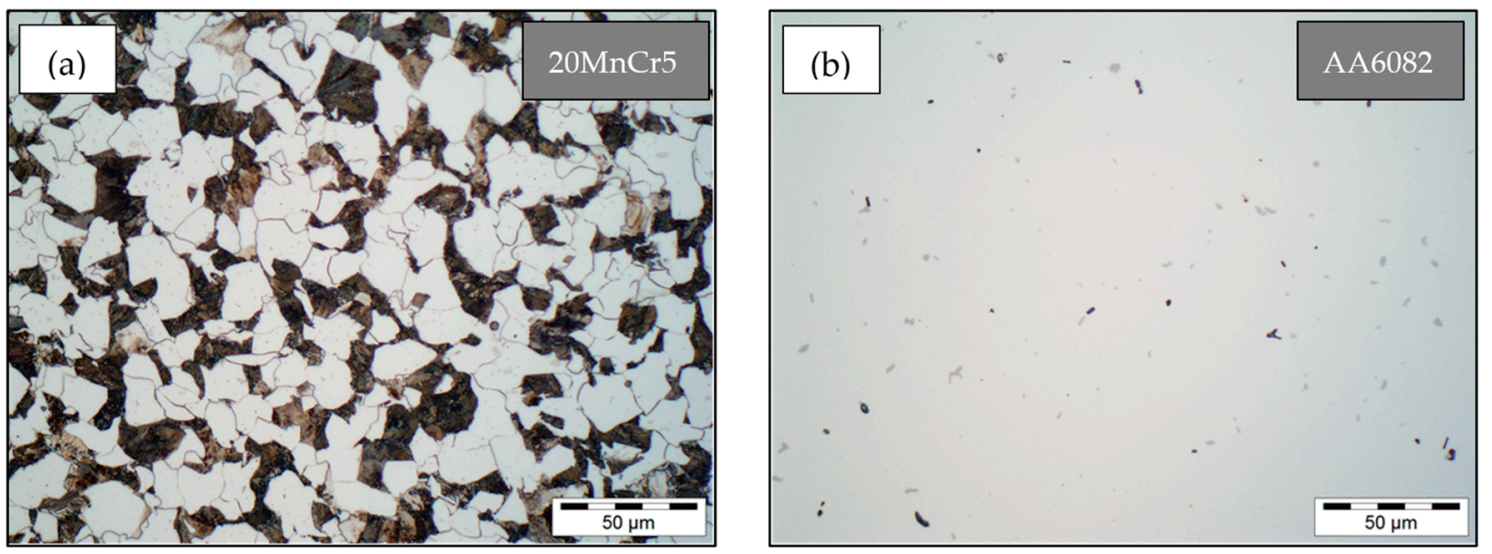

Figure 2. (a) Ferritic-pearlitic microstructure of the $20 \mathrm{MnCr} 5$ steel in the soft annealed condition, etched with Nital (3\%), and (b) unetched micrograph of the AA6082 aluminum alloy (T6 condition).

\subsection{Friction Surface Geometries}

The different surface geometries of the semifinished products investigated were chosen to improve the joining zone properties by surface enlargements, undercuts and shrinkage. An increase in the friction surface leads to a higher temperature generation, from which a lower demand for the yield forces results. As described in the literature [10], air pockets can occur in the center of the specimen for flat surfaces. With higher temperatures, these can be avoided. An undercut results in a form fit or force fit, depending on whether the aluminum fills a hole by flowing or encloses a shape by shrinking. The geometries, manufactured by machining, are depicted in Figure 3.

Geometry A (Figure 3) was selected for a form-locking connection to enhance the bonding strength. During friction welding, the undercut of the cavity located in the steel part with an angle of $75^{\circ}$ was filled with aluminum. On the basis of preliminary tests, an angle of $75^{\circ}$ was determined to be optimum, since at this angle complete mold-filling can be ensured, despite a relatively concise form fitting. Geometry B offers an enlarged friction surface due to the hemispherical geometry, which results in a higher heat generation due to friction. The shoulder at the transition from the hemisphere was designed with a beveled edge to improve material flow. Geometry $C$ features four drilled holes intended to increase the torsional stiffness by means of flowing aluminum entering the holes, thus achieving a form lock. Geometry D forms a hemispherical surface, resulting in an enlarged friction surface analogous to Geometry B. The difference to Geometry B is the absence of a shoulder to examine its necessity for the material flow.

Conical geometries were welded with varying angles of $30^{\circ}$ (Geometry E) and $45^{\circ}$ (Geometry G) using an increased friction contact surface and reduced manufacturing effort compared to the hemispherical Geometry B. The conical Geometry G is additionally truncated to simplify production and to combine an axial force with directed material flow during the forming process. Compared to Geometry A, Geometry F has no cavity in the steel component. The undercut was formed by a protruding elevation with an angle of $80^{\circ}$, while the aluminum is of a flat geometry. The aluminum was intended to flow around the shoulder and shrink to the steel due to the greater thermal expansion coefficient. In addition to the form lock and material bond, this geometry provides a force-locked connection to enhance the bonding strength. Preliminary tests have shown that too large a pin or an angle smaller than $80^{\circ}$ will result in air pockets. Geometry $\mathrm{H}$ has a pin on the aluminum side to investigate the influence of the expected deformation ratio and the high friction path on the bonding strength (Table 3). 


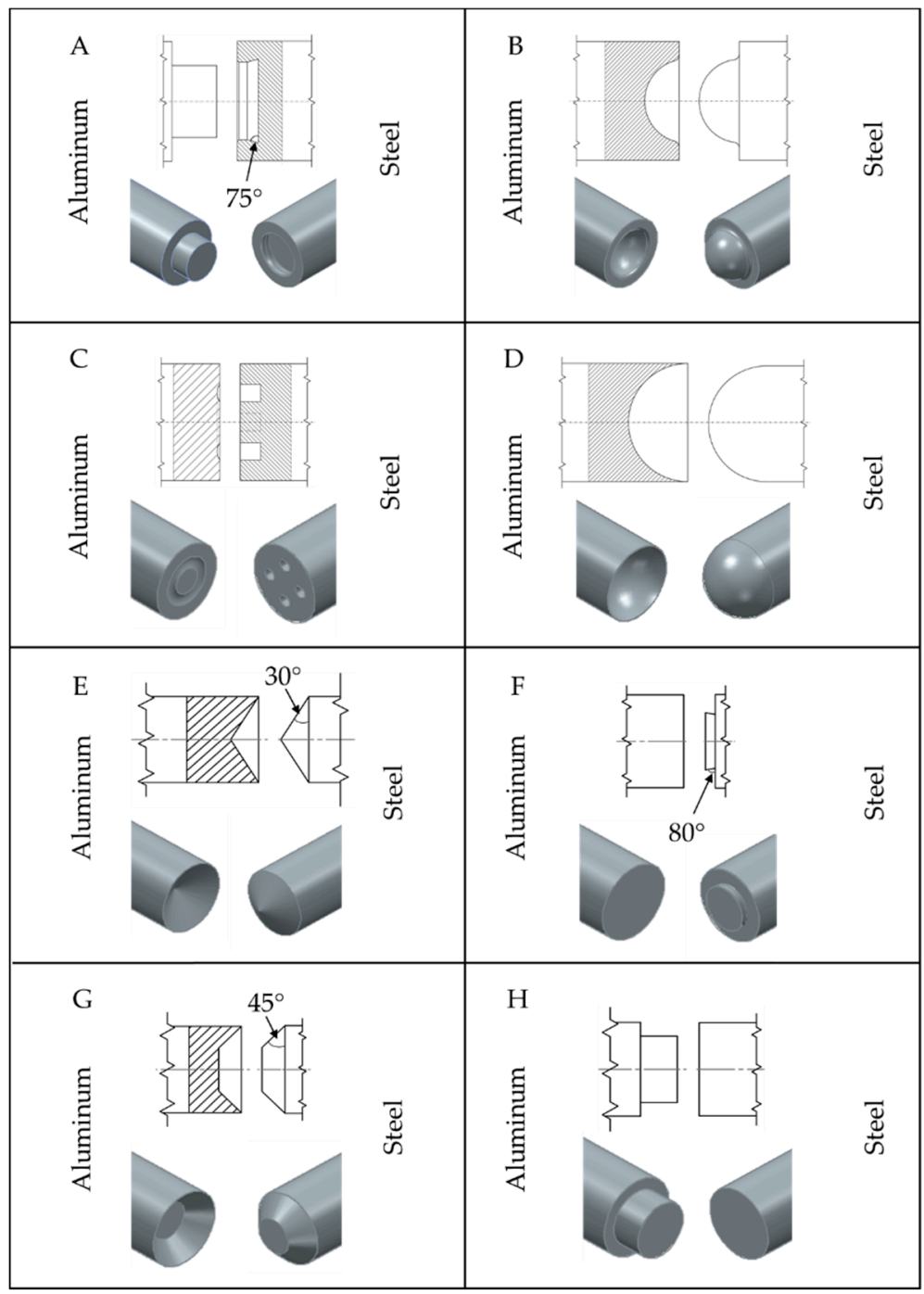

Figure 3. Geometries of friction surfaces (A-H), outer diameters of $40 \mathrm{~mm}$.

Table 3. Main parameters of the friction welding process.

\begin{tabular}{ccccccccc}
\hline Geometry & A & B & C & D & E & F & G & H \\
\hline Friction speed in 1/min & 1500 & 1500 & 1500 & 1500 & 2000 & 2000 & 2000 & 2000 \\
Frictional force in kN & 150 & 100 & 80 & 80 & 70 & 75 & 70 & 75 \\
Friction time in s & - & 2 & 2 & 0.05 & 0.1 & - & 0.1 & - \\
Relative friction path in mm & 4 & - & - & - & - & 4 & - & 10 \\
Press force in kN & 240 & 120 & 150 & 120 & 120 & 150 & 120 & 120 \\
Press time in s & 2 & 1 & 2 & 1 & 2 & 2 & 2 & 2 \\
\hline
\end{tabular}

\subsection{Friction Welding}

At first, the geometries presented above were cleaned in an ultrasonic bath filled with ethanol. After drying, these were friction-welded on a KUKA Genius Plus (Kuka AG, Augsburg, Germany). The most important process parameters are listed in Table 3. The parameters were selected according to prior investigations. For comparability, most parameters were chosen to be identical or limited to a few varying values according to the different geometries. Parameters with varying values were selected since these resulted in similar shapes and qualities of the bonding, according to first visual examinations.

The major differences between the performed welding processes of the first four geometries and the second four are the following: The friction speed was increased from 
1500 to $2000 \mathrm{rpm}$ for Geometries E, F, G and H to ensure a convenient heat generation at lower friction forces. Lower frictional forces were chosen for the second four geometries to prevent undesired deformations during the friction phase. In order to investigate the influence of high true strain, the friction path of Geometry $\mathrm{H}$ was increased in comparison to the path-controlled processes of Geometries A and F.

\subsection{Metallographic Analysis}

Following the friction welding process, the samples were cut along the axis of rotation and the cross section of the joining zones were prepared for metallographic examinations by grinding, polishing and etching. The quality of the joining zone was analyzed on micrographs by detecting phases and inclusions. In addition, the Vickers hardness was measured according to DIN EN ISO 6507-1 [17] (HV0.1) to compare the mechanical properties of the joining zone and of the heat-affected zones with those of the base materials. Furthermore, the joining zone was analyzed by scanning electron microscopy (SEM) (AURIGA from Zeiss, Oberkochen, Germany) and energy dispersive X-ray spectroscopy (EDS) (Oxford Instruments, Abingdon, UK). A slope cut was prepared by applying a focused ion beam (FIB) to excavate a cross section not influenced by prior conventional steps of metallographic preparations.

\subsection{Mechanical Testing}

Tensile tests were carried out for all geometries to determine the tensile strength and to evaluate the bonding strength. For each geometry two samples were tested on a Zwick Z250 kN (ZwickRoell GmbH \& Co. KG, Ulm, Germany) with the preload force of $300 \mathrm{~N}$, the clamping pressure of $30 \mathrm{MPa}$ and the strain rate of $0.002 \mathrm{~s}^{-1}$. The geometry of the tested tensile specimen is depicted in Figure 4, which was manufactured out of the friction welding products with a reduced diameter for the gauge length. The joining zone is not located at the center of the tensile specimens due to the geometry of the welding products. Besides the decentralized joining zone, the results of the tensile tests reveal no irregularities, since necking did not occur or was located within the gauge length.

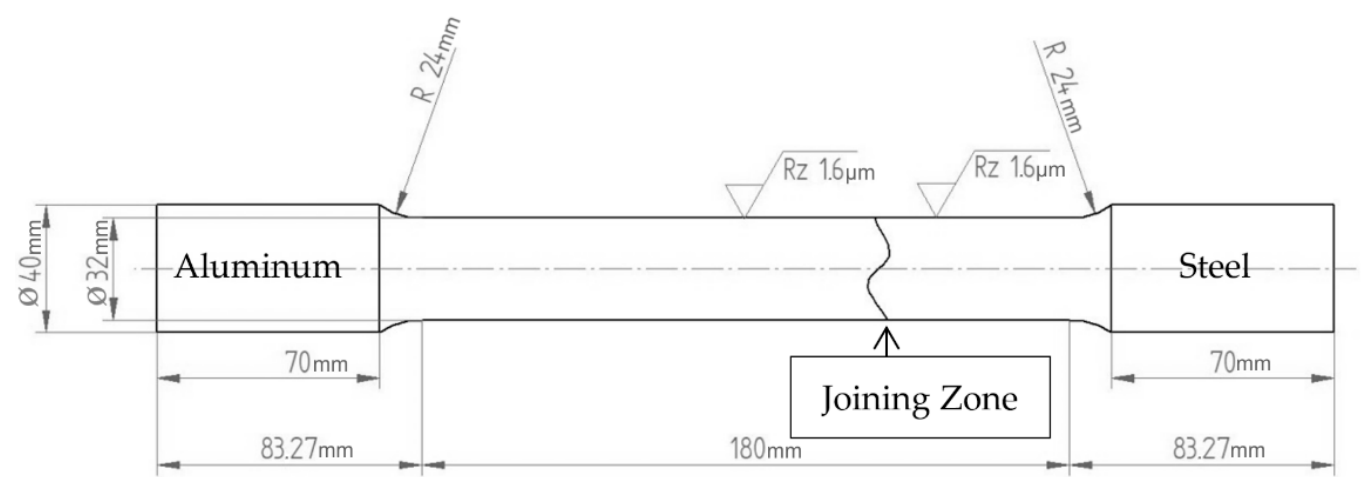

Figure 4. Geometry of tensile samples with highlighted position of the joining zone, according to DIN EN ISO 6892-1 [18], in millimeters.

\section{Results}

The following sections present the results of the different testing methods. These include the determination of mechanical parameters as well as metallographic investigations.

\subsection{Tensile Test}

In Figure 5 the stress-strain curve of a sample of Geometry A is exemplarily depicted on the left side and a comparison of the samples with the highest tensile strengths $R_{m}$ is presented on the right side. 


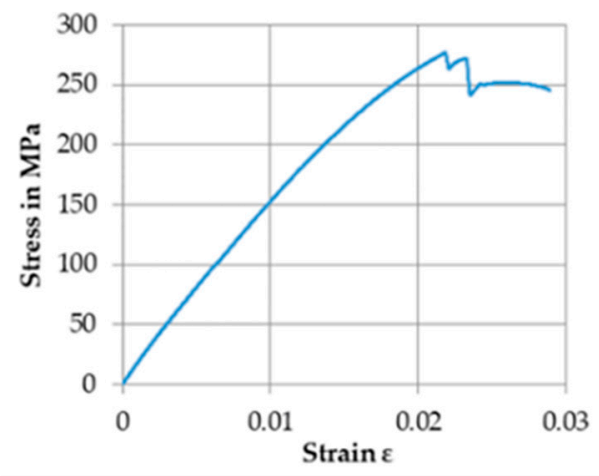

(a)

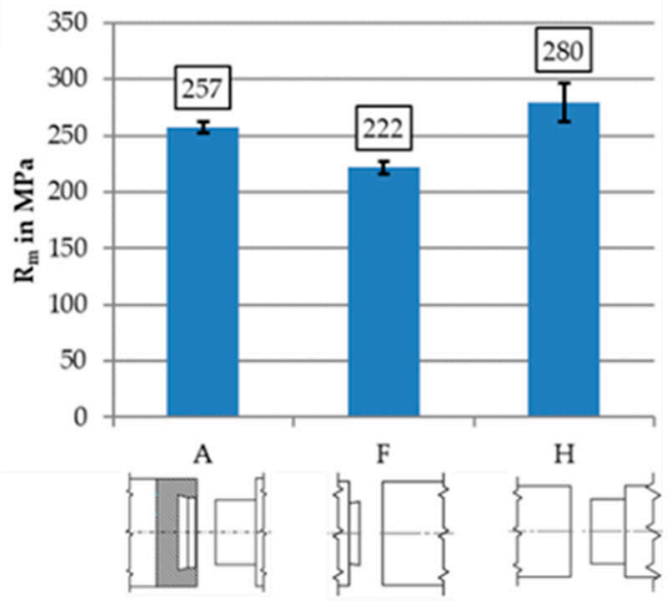

(b)

Figure 5. (a) stress-strain curve of Geometry A; (b) schematic drafts of the specimen geometries featuring the highest tensile strengths values with the standard deviation.

The tensile tests show that though the tensile strength $R_{m}$ achievable with the various geometries differs, the qualitative shapes of the curves are almost identical. Fracture in the joining zone occurs due to brittleness of all geometries except Geometry A (confer Figure 6). An increased elongation at fracture is only visible in the stress-strain curve of Geometry A; here, reaching the stress maximum (Figure 5, at a strain of 0.022) a lateral contraction of the aluminum alloy can be observed.

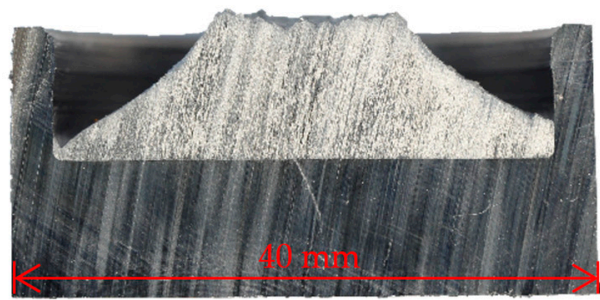

(a)

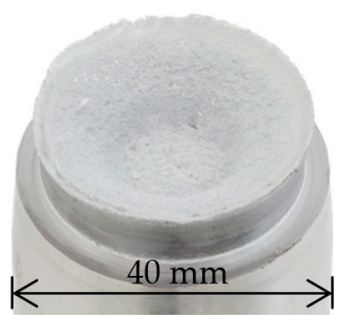

(b)

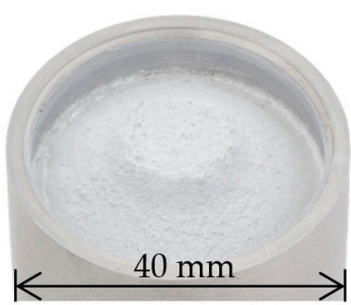

(c)

Figure 6. Specimen of Geometry A after tensile testing: (a) cross section; (b) aluminum side; (c) steel side.

All specimens have brittle fractures. Just specimens of Geometry A have a necking (Figure 5) and more remains of the aluminum (Figure 6) than other specimens. Figure 6 shows one specimen of Geometry A after tensile testing.

\subsection{Metallography}

In the following, cross sections of the specimens of Geometries B, C, D, E and F are depicted to show exemplary bonding defects. The Geometries A, G and $\mathrm{H}$ feature the desired bonding quality and visible defects such as gas pores, inclusions or cracks are not present in the joining zone.

Figure 7 gives an overview of the Geometries B (a) and D (b). The plotted angles mark the direction of the material flow when the aluminum alloy is detached from the steel. The bond of sample Geometry B is almost complete. At an angle of approximately $15^{\circ}$, the bond starts detaching and closes again in the shoulder area. This results in air inclusions and is a weak point over the complete circumference of the joint. The reason for this is the material flow which is indicated schematically by the violet arrows in Figure 7a. 
(a)

B

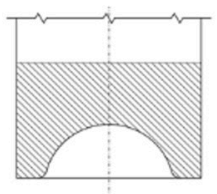

(b)

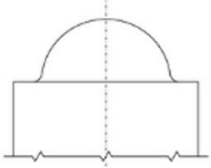

$\mathrm{D}$
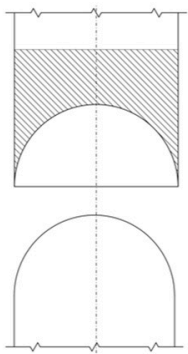

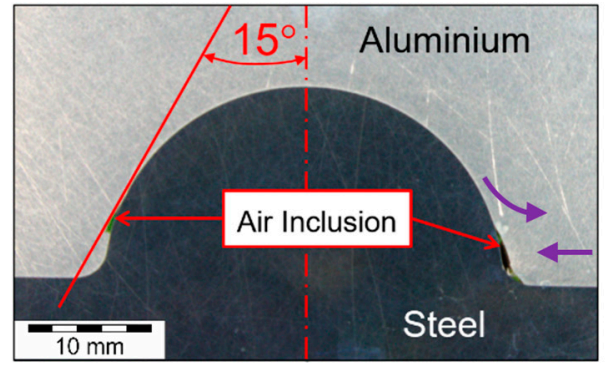

$=$ Material Flow

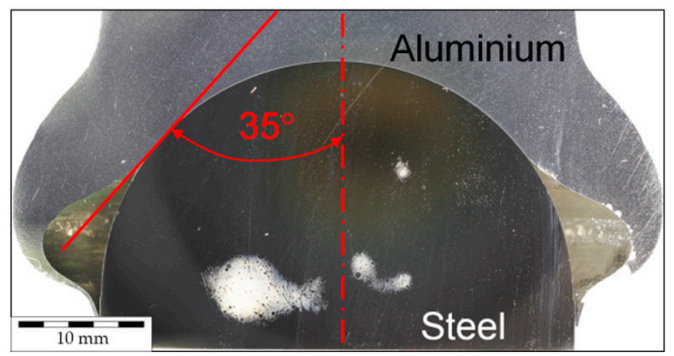

Figure 7. (a) Cross section of Geometry B and (b) cross section of Geometry D; the angles mark the detachment of the aluminum.

At Geometry D (Figure 7b), the aluminum alloy peels off at an angle of $35^{\circ}$ and does not get into further contact. The material flow and the applied forces possibly cause the detachment in both geometries.

Geometry C is depicted in Figure 8. A complete filling of the holes was not achieved and gaps on the circumference occur with increasing depth; additionally, fragments of the aluminum alloy are visible.

C
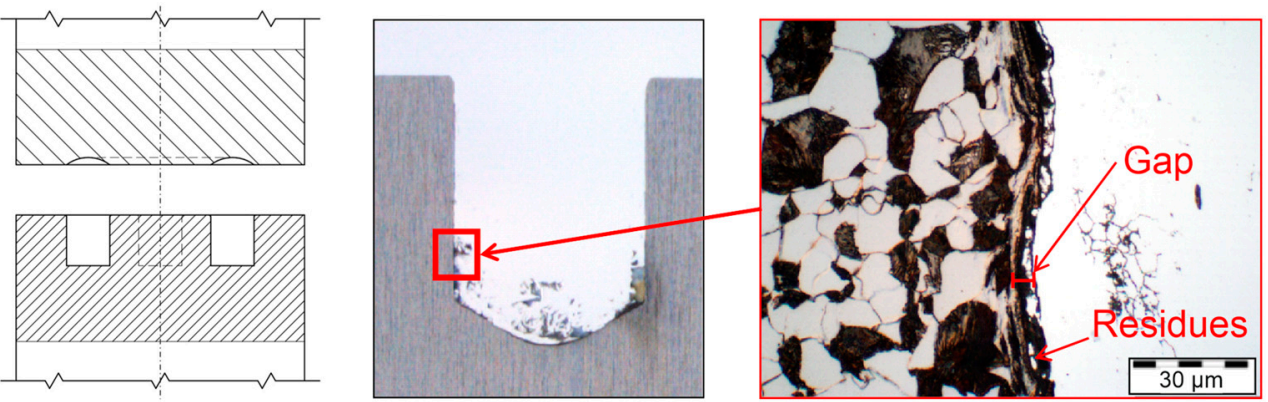

Figure 8. Geometry C, (left) schematic draft, (middle) overview of a filled borehole, and (right) exemplary gap at the borehole flank.

A section of Geometry E is depicted in Figure 9. The bond is complete except for higher radii, where air inclusions at diameters of 37 to $40 \mathrm{~mm}$ can be seen. For Geometry F, a small air inclusion appears near the undercut. This area is displayed in Figure 10.

The hardness of the samples was measured at different distances across the joining zone to characterize the influence of the generated heat and the forming during the friction welding process. It can be assumed that the size of the grains and the concentration of elements are influenced by the heat resulting in varying hardnesses compared to the basic materials. The space between two recording points in the aluminum alloy was chosen according to DIN EN ISO 6507-1 [17]. For simplification, the same distance of $0.5 \mathrm{~mm}$ was used in the steel. Figure 11 gives an example (Geometry F) of the measurements. The transition area could not be narrowed down due to the limiting conditions. 
E
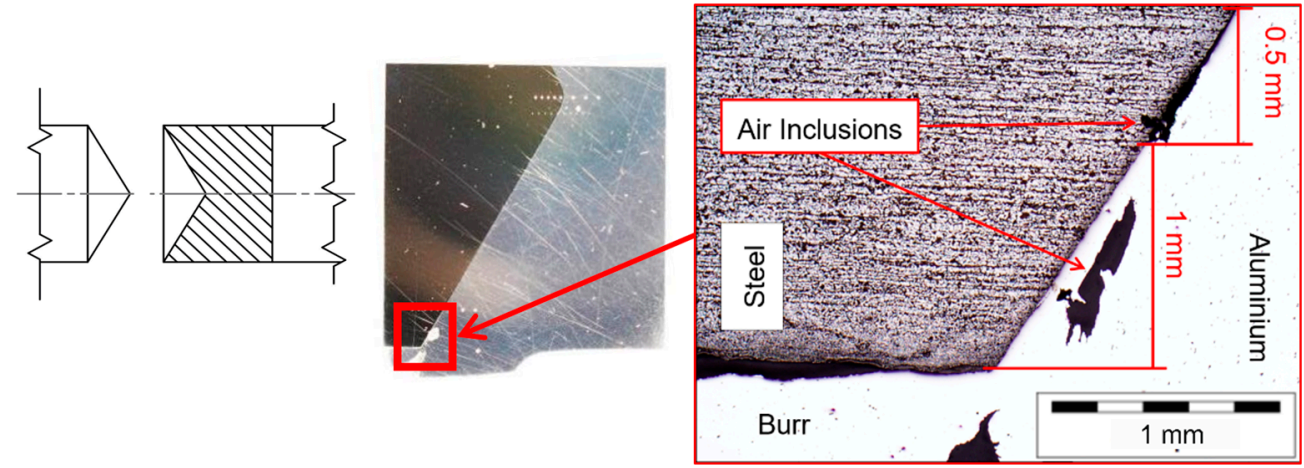

Figure 9. Geometry E, (left) schematic draft, (middle) overview of a half-cut sample, and (right) example of air inclusions in regions of the increased diameter.

F

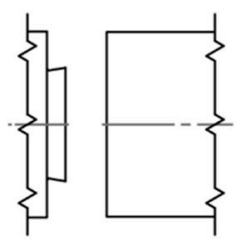

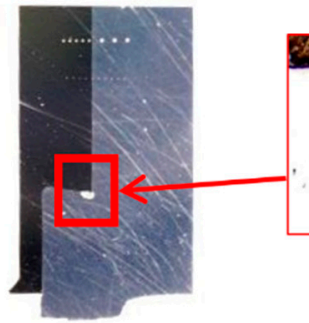

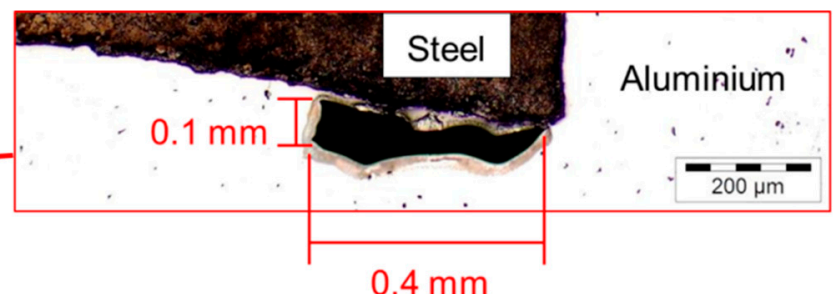

Figure 10. Geometry F, (left) schematic draft, (middle) overview of a nearly half-cut sample, and (right) exemplary air inclusion at the undercut.

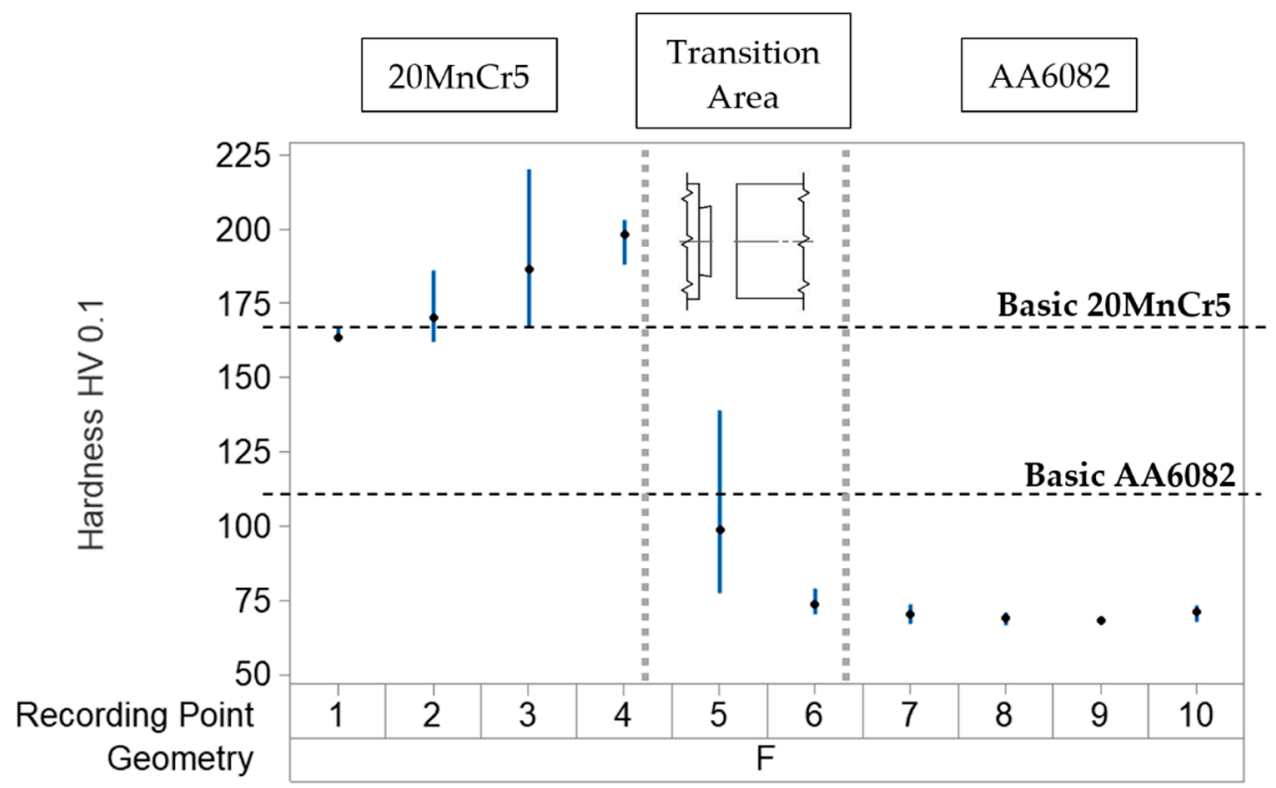

Figure 11. Diagram of the hardness of a sample with Geometry F including the variance, range between recording points is approximately $0.5 \mathrm{~mm}$.

On the steel side, almost all samples show a small increase in hardness for the measuring point closest to the transition area-for example, recording point 4 in Figure 11. The soft annealed base material has an average hardness of 170 HV0.1 and is marked in Figure 11 as a horizontal dotted line. It can be concluded that some samples have experienced a slight softening and others an increase in steel hardness further from the interface in the axial direction. 
The aluminum alloy has an average hardness of 113 HV0.1 in the T6 condition. Close to the joining zone the aluminum becomes softened and has an average hardness below 75 HV0.1, as can be seen for Geometry F in Figure 11. Geometry E is the only exception where a hardness of 103 HV0.1 was determined, possibly caused by a lower heat generation.

To investigate the joining zone, micrographs were examined. Two different types of interlayers between steel and aluminum alloys were found in the metallographic analyses. The first layer is located on the aluminum side near the friction welding surface and has a darker color. Figure 12 depicts an analyzed example of such a layer. Its thickness varies up to $1.5 \mu \mathrm{m}$. It is mainly found on flat areas of the friction surfaces-for example, in the undercut in Geometry A around the central axis. Since it was not possible to characterize the layer in detail by light microscopy, scanning electron microscopy was applied (confer Section 3.3).

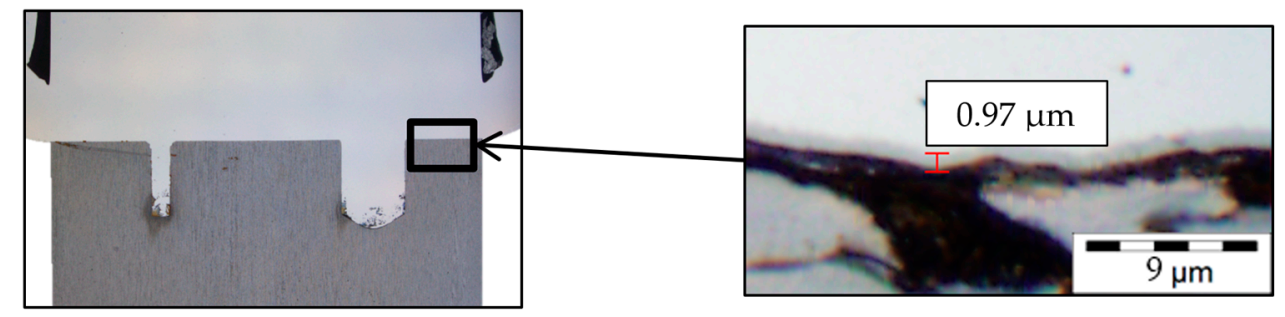

Figure 12. (Left) overview of Geometry $C$, and (right) dark layer on the aluminum side close to the joining zone.

The second layer found close to the joining zone, is a layer of fine-grained steel microstructures with increasing degree of fineness from the basic steel to the interface. Its thickness increases with the diameter from about 0.5 up to $3 \mu \mathrm{m}$ (Figure 13).

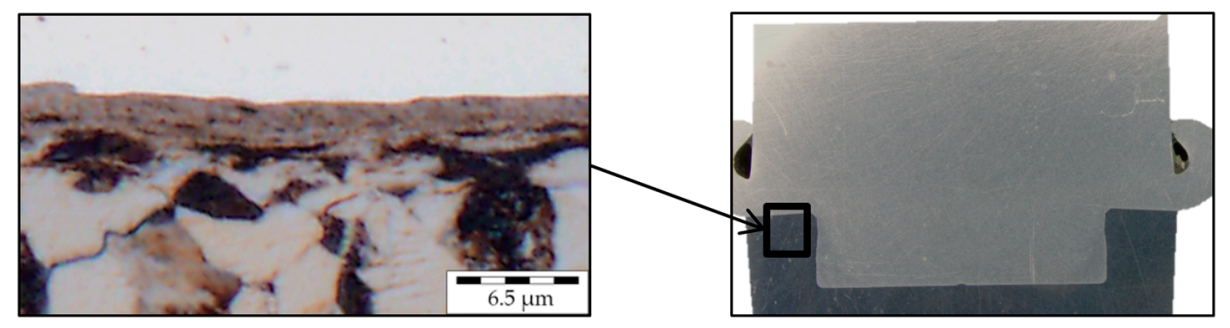

Figure 13. (Left) fine-grained layer on the steel side close to the joining zone and (right) overview of Geometry A.

\subsection{Scanning Electron Microscopy}

To identify the darkened layers described in Section 3.2, EDS analyses were carried out via a scanning electron microscope using a sample of Geometry $\mathrm{C}$. This sample was chosen due to the clear formation of the darkened layer (Figure 12). Figure 14 depicts the cross section prepared by a FIB with the highlighted recording line of the EDS measurement. The results of the EDS analysis are given in Figure 15 and illustrate the chemical composition of the elements along the marked line. 


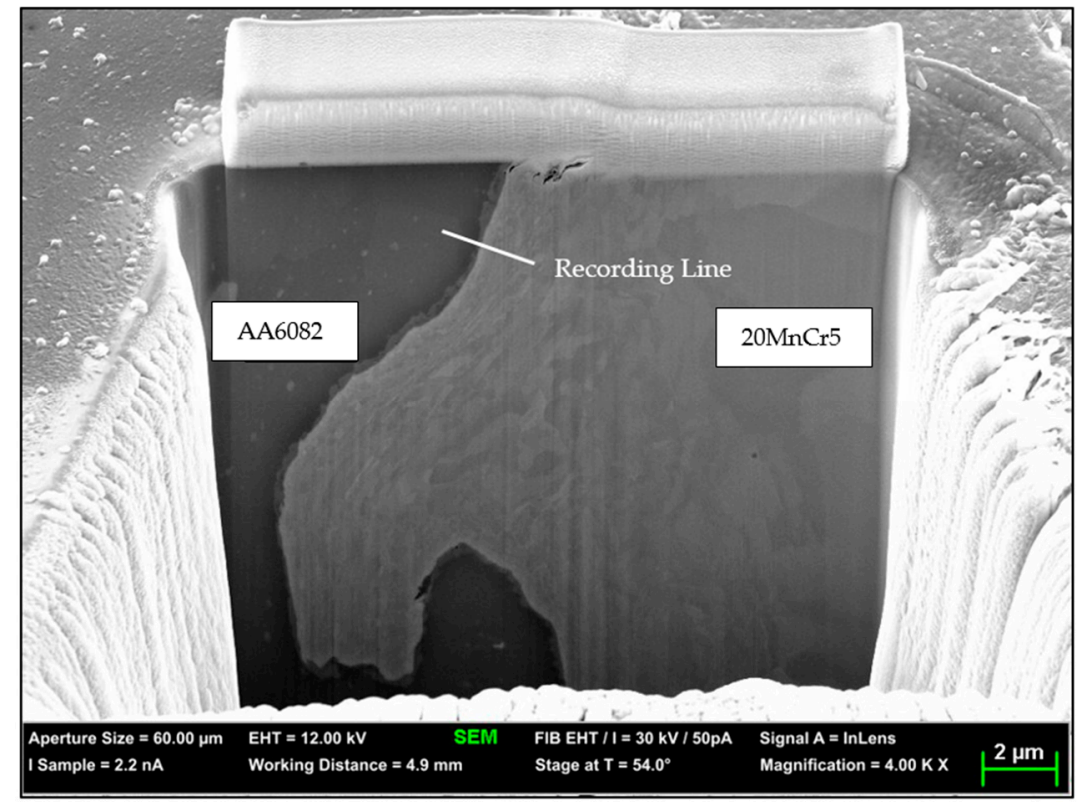

Figure 14. Scanning electron microscopy (SEM) image of a cross section prepared by a focused ion beam (FIB) in-lens detector (sample of Geometry C).

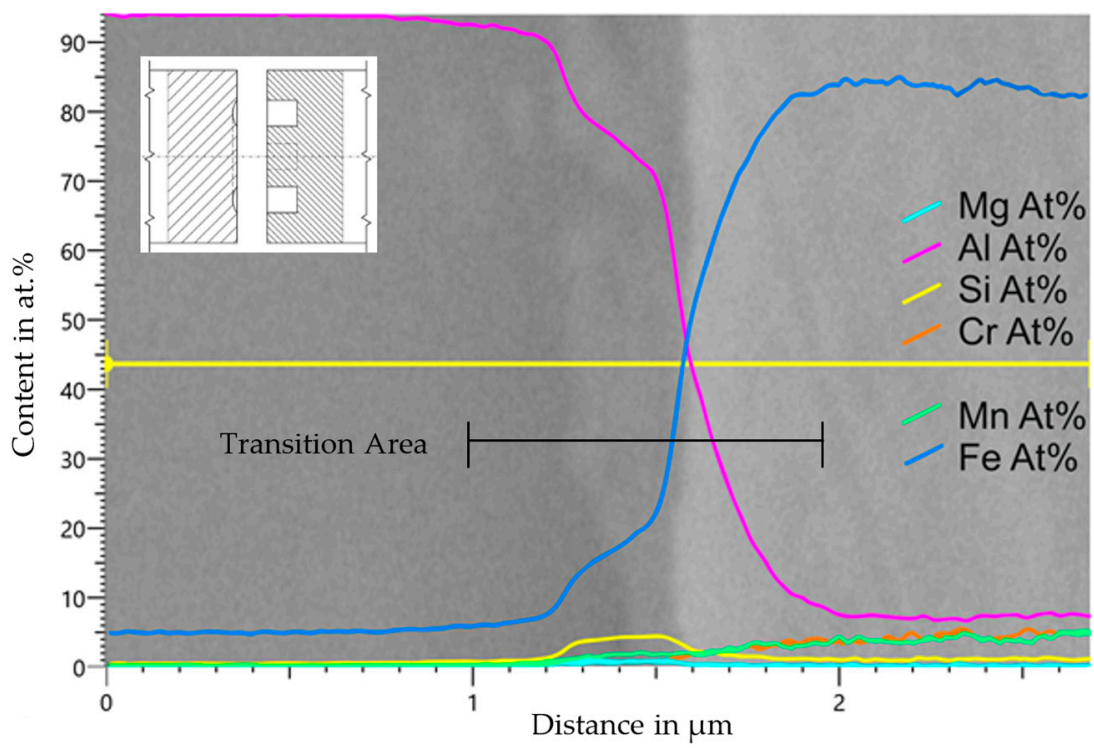

Figure 15. Energy-dispersive $X$-ray spectroscopy (EDS) analysis of the transition area in a specimen of Geometry C, SEM image of the recording line (yellow), Electron High Tension (EHT) $=12 \mathrm{kV}$, probe current $=1.7 \mathrm{nA}$, and working distance $=4.9 \mathrm{~mm}$.

The left side of the graph in Figure 15 depicts the base material composition of the aluminum alloy. A content of almost 5 at.\% of diffused iron is noticeable. On the right side of the graph, the composition of the steel base material is displayed, which contains a certain amount of alloying elements. Akin to the diffused iron on the aluminum side, aluminum diffused into the steel side with a content of about 5 at.\%. Furthermore, an increased occurrence of manganese, magnesium and silicon can be observed in the transition zone. A mapping of the silicon content reveals its enrichment within a zone of about $0.5 \mu \mathrm{m}$ as can be seen in Figure 16. 


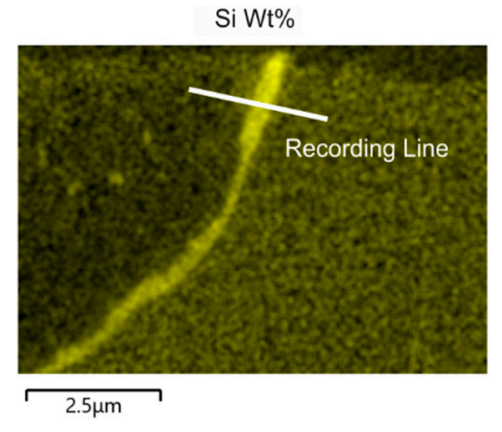

(a)

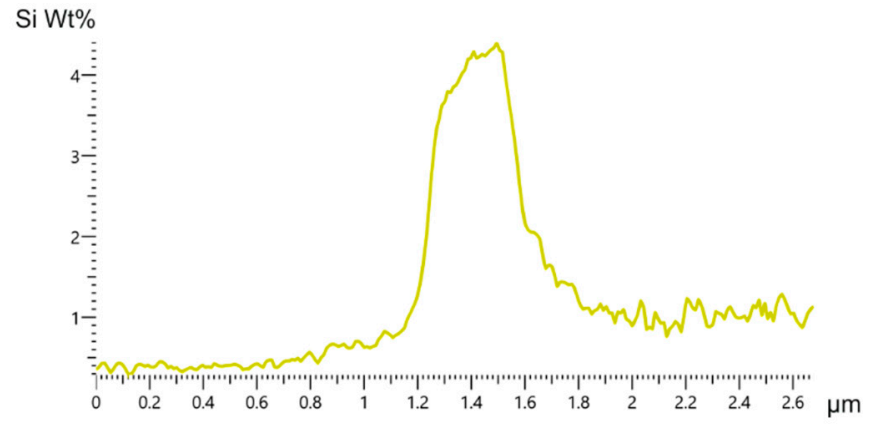

(b)

Figure 16. EDS analysis of a sample with Geometry C, (a) distribution of silicon, and (b) silicon content in wt.\% near the joining zone.

High silicon contents on sample surfaces can result from conventional sample preparation with silicon carbide grinding discs when a slope is formed in the joining zone during preparation due to the large differences in strength between aluminum and steel [19]. Silicon carbide particles can thus accumulate at the slope. Since in this case the EDS measurement was carried out on a cross section prepared using a FIB, such an influence of the preparation can be excluded.

Here, the increased silicon content measured in the joining zone by an EDS analysis is in accordance with observations of Liu et al. and Wang et al., who also reported increased silicon concentrations in the intermetallic compound (IMC) layer in the joining zone in investigations on friction welding of aluminum and steel $[20,21]$. The silicon is incorporated into the IMC layer and slows down the growth of the IMC layer [22]. With increasing silicon content in the aluminum alloy, the thickness of the IMC layer is reduced, and the phase constitution of the aluminide layers is altered [23].

\section{Discussion}

The presented results reveal that the surface geometry of friction-welded semifinished products and the parameters of the friction welding process have a decisive impact on the resulting bond and its strength. For example, Figure 14 shows microinterlocking, which may result from the different contact areas of the various geometries generating different temperatures during the friction process. This interlocking can result in an improvement of the bonding strength. Additionally, the different generated temperatures can lead to different microstructures, such as the grain size or the thickness of a possible intermetallic phase, and further in different bonding strengths.

Micrographs of the cross sections reveal that the material flow has an impact on the completeness of the bond. For example, for Geometry B (Figure 7a), air inclusions occur due to the resulting material flow. The aluminum alloy flowed outwards over the dome and detached from the $20 \mathrm{MnCr} 5$ steel. In addition, it can be assumed that some of the aluminum alloy was pushed back inwards onto the shoulder due to the colder outer zone, which has a higher deformation resistance. Another example of the importance of the material flow are the boreholes of Geometry C (Figure 8), which were not fully filled by flowing aluminum. The pressure of the enclosed air inside the boreholes inhibited a complete filling. Higher temperatures generated by rotational speed or pressure would increase the degree of deformation. This could lead to a better material flow.

The hardness tests show a decisive influence of the processing as a small increase in the hardness on the steel side near transition area (confer Figure 11). This hardness increase is probably caused by a combination of strain hardening due to the deformation process and grain refinement in the joining zone or by the occurrence of harder phases such as an intermetallic phases. An indication for the latter might be the multiple changes of the slope visible in the EDS line scan at the aluminum side in Figure 15 and the similarity of the darker layer in Figure 12 compared to the literature, such as [15]. 
Contrary to the hardness increase in the steel, the aluminum became softened close to the transition area which can probably be attributed to recrystallization or overageing of the T6 state due to heat generation during the friction welding process. In the transition area, the hardness decreased gradually between steel and aluminum, caused by mutual diffusion of aluminum and iron. An example of the concentration profile across the transition area is depicted in Section 3.3, Figure 15.

Hardness itself does not account for the quality of a bond, but it correlates with the tensile strength. Summarized, the hardness measurements reveal a heat-affected zone in both materials and in between them but could not be narrowed down due to the limiting conditions.

For the intended following impact extrusion process, Geometries A, F and $\mathrm{H}$ show the most promising results in mechanical tests and metallographic analyses. They feature a nearly complete bonding and high tensile strengths above $220 \mathrm{MPa}$. Only Geometry F contains a small volume of air inclusions at the undercut, which can possibly be avoided using modified parameters of the friction welding process. All specimens exhibited brittle fractures except for Geometry A. Brittle fractures underline the possible presence of (brittle) intermetallic phases [15]. Geometry $\mathrm{H}$ has the highest tensile strength of almost $280 \mathrm{MPa}$ which is $100 \mathrm{MPa}$ lower than the tensile strength of the base material (over $360 \mathrm{MPa}$ ), thus reaching about $77 \%$ of the base strength. Regarding the future processing by subsequent heating and impact extrusion, a recrystallization of the microstructure in the transition area can be expected and might further increase the bonding strength. With the evaluated bonding strength, Geometries $\mathrm{A}, \mathrm{F}$ and $\mathrm{H}$ are hence suited for the subsequent inductive heating and forming process.

\section{Summary and Conclusions}

Based on the presented results, the following conclusions can be drawn:

- The highest tensile strengths values have been achieved using Geometries A (257 MPa), $\mathrm{F}(222 \mathrm{MPa})$ and $\mathrm{H}(280 \mathrm{MPa})$ (flat surface: $252 \mathrm{MPa}$ in [14]);

- The completeness of the joint differs depending on the geometry and the correlation to the parameters of the friction welding process;

- The hardness close to the transition area was influenced by thermal effects of the friction welding process, resulting in a softening of the aluminum and an increased hardness in the steel;

- The EDS analysis showed what is most likely an intermetallic phase at the joining zone with a high content of silicon.

Table 4 presents the geometries investigated, their bond strengths and the main comments with regard to the further process chain of the CRC 1153.

Table 4. Results of the different geometries with regard to the further process.

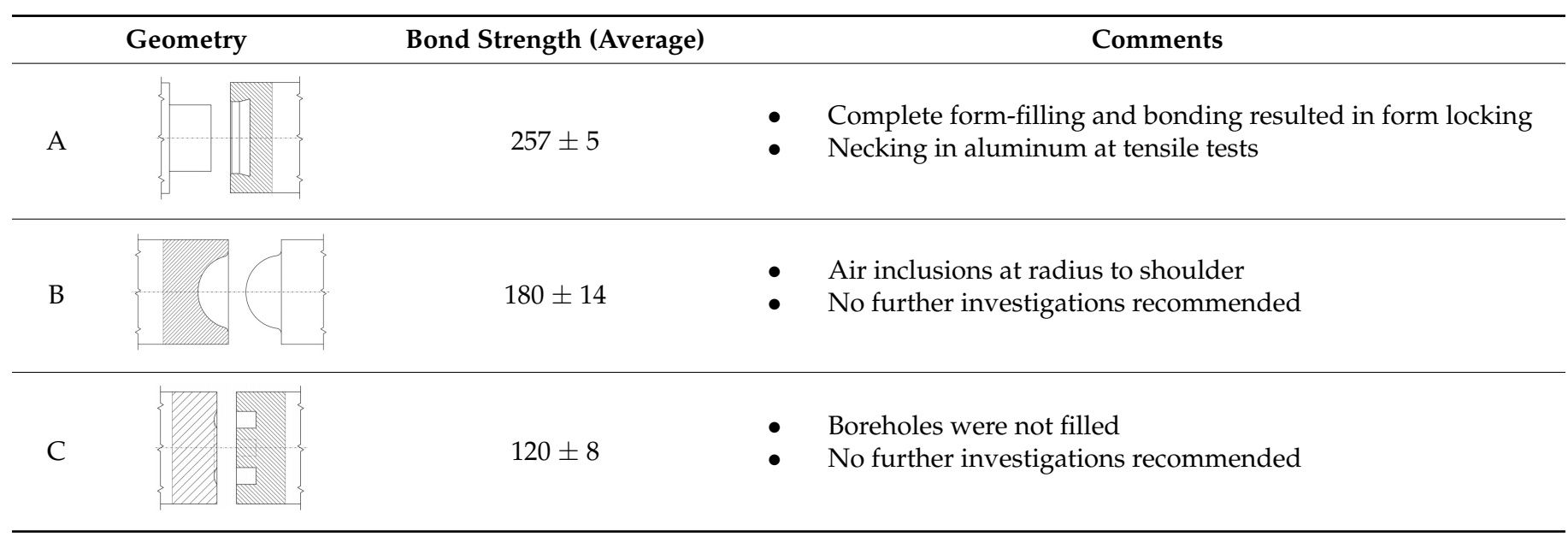


Table 4. Cont.

\begin{tabular}{|c|c|c|c|}
\hline & Geometry & Bond Strength (Average) & Comments \\
\hline $\mathrm{D}$ & & $190 \pm 15$ & $\begin{array}{l}\text { - } \quad \text { Incomplete bonding } \\
\text { - } \quad \text { No further investigations recommended }\end{array}$ \\
\hline $\mathrm{E}$ & & $180 \pm 21$ & $\begin{array}{l}\text { - Air inclusions at outer diameter could be eliminated by using } \\
\text { different friction parameters }\end{array}$ \\
\hline $\mathrm{F}$ & & $222 \pm 5$ & $\begin{array}{l}\text { - } \quad \text { Small air inclusion at the undercut } \\
\text { - } \quad \text { Suitable for inductive heating } \\
\text { - } \quad \text { Shrinkage resulted in force- and form-locking }\end{array}$ \\
\hline G & & $215 \pm 4$ & $\begin{array}{l}\text { - } \quad \text { Complete bonding } \\
\text { Bond strength could be enhanced by using different friction } \\
\text { parameters }\end{array}$ \\
\hline $\mathrm{H}$ & & $280 \pm 17$ & - Complete bonding \\
\hline
\end{tabular}

The influence of various factors, such as friction welding parameters and material choice, leads to a large spectrum of possible improvements for enhancing the bonding strength. For example, the integrity of the joining zone might be improved by increasing heat generation during processing and thus diffusion of the alloying elements, though grain growth is to be expected. Hence, further investigations will focus on specimens with fixed surface geometries but varied friction welding parameters-e.g., a modification of Geometry $\mathrm{F}$ with an undercut angle of $80^{\circ}$ on the steel side is to be expected promising regarding a further increase in the bonding strength. With this geometry, not only material bonds but force and form locks as well can be accomplished without a significant penetration of the aluminum alloy on the steel side, which otherwise could lead to a premature melting of the aluminum during induction heating in the further processes within the process chain of the CRC 1153 [8].

Author Contributions: Conceptualization, J.U. and B.-A.B.; methodology, R.L. and I.R.; validation, I.R., T.P., F.N. and J.U.; investigation, R.L. and I.R.; writing-original draft preparation, R.L.; writingreview and editing, J.U., T.P., F.N., C.K. and I.R.; visualization, R.L. and I.R.; supervision, B.-A.B., T.P. and J.U.; project administration, B.-A.B. and J.U.; funding acquisition, B.-A.B. All authors have read and agreed to the published version of the manuscript.

Funding: Funded by the Deutsche Forschungsgemeinschaft (DFG, German Research Foundation)CRC 1153, subproject B3-252662854. The authors thank the German Research Foundation (DFG) for their financial support of this project.

Institutional Review Board Statement: Not applicable.

Informed Consent Statement: Not applicable.

Data Availability Statement: The data presented in this study are available in the article.

Acknowledgments: The authors appreciate the support of the subproject A2 regarding tensile testing and of Torsten Heidenblut regarding the SEM investigations.

Conflicts of Interest: The authors declare that they have no known competing financial interests or personal relationships that could have appeared to influence the work reported in this paper. 


\section{References}

1. Erman Tekkaya, A. Energy saving by manufacturing technology. Procedia Manuf. 2018, 21, 392-396. [CrossRef]

2. Lancaster, J.F. Metallurgy of Welding; Springer: Dordrecht, The Netherlands, 1980; ISBN 978-94-010-9508-2.

3. Friedrich, H.E. Leichtbau in der Fahrzeugtechnik; Springer Fachmedien Wiesbaden: Wiesbaden, Germany, 2013; ISBN 978-3-83481467-8.

4. Hootak, M.; Kuwert, P.; Behrens, B.-A. (Eds.) Numerical Process Design for Compound Forging of Powder-Metallurgical and Solid Dissimilar Workpieces. In Proceedings of the 8th Congress of the German Academic Association for Production Technology (WGP), Aachen, Germany, 19-20 November 2018.

5. Thomä, M.; Gester, A.; Wagner, G.; Straß, B.; Wolter, B.; Benfer, S.; Gowda, D.K.; Fürbeth, W. Application of the hybrid process ultrasound enhanced friction stir welding on dissimilar aluminum/dual-phase steel and aluminum/magnesium joints. Mater. Werkst. 2019, 50, 893-912. [CrossRef]

6. Behrens, B.-A.; Huskic, A.; Bouguecha, A.; Frischkorn, C.; Chugreeva, A.; Duran, D. Tailored Forming Technology for Three Dimensional Components: Approaches to Heating and Forming. In Proceedings of the 5th International Conference on Thermomechanical Processing, Milan, Italy, 26-28 October 2016.

7. Behrens, B.-A.; Bonhage, M.; Bohr, D.; Duran, D. Simulation Assisted Process Development for Tailored Forming. Mater. Sci. Forum 2019, 949, 101-111. [CrossRef]

8. Behrens, B.-A.; Goldstein, R.; Duran, D. Role of Thermal Processing in Tailored Forming Technology for Manufacturing MultiMaterial Components. In Proceedings of the Heat Treat 2017: Proceedings of the 29th ASM Treating Society Conference, Columbus, OH, USA, 24-26 October 2017.

9. Ashfaq, M.; Sajja, N.; Khalid Rafi, H.; Prasad Rao, K. Improving Strength of Stainless Steel/Aluminum Alloy Friction Welds by Modifying Faying Surface Design. J. Mater. Eng. Perform. 2013, 22, 376-383. [CrossRef]

10. Fukumoto, S.; Tsubakino, H.; Okita, K.; Aritoshi, M.; Tomita, T. Friction welding process of 5052 aluminium alloy to 304 stainless steel. Mater. Sci. Technol. 1999, 15, 1080-1086. [CrossRef]

11. Lee, W.B.; Yeon, Y.M.; Kim, D.U.; Jung, S.B. Effect of friction welding parameters on mechanical and metallurgical properties of aluminium alloy 5052-A36 steel joint. Mater. Sci. Technol. 2003, 19, 773-778. [CrossRef]

12. Fukumoto, S.; Inuki, T.; Tsubakino, H.; Okita, K.; Aritoshi, M.; Tomita, T. Evaluation of friction weld interface of aluminium to austenitic stainless steel joint. Mater. Sci. Technol. 1997, 13, 679-686. [CrossRef]

13. Sahin, M. Joining of stainless-steel and aluminium materials by friction welding. Int. J. Adv. Manuf. Technol. 2009, 41, 487-497. [CrossRef]

14. Behrens, B.-A.; Chugreev, A.; Selinski, M.; Matthias, T. Joining zone shape optimisation for hybrid components made of aluminiumsteel by geometrically adapted joining surfaces in the friction welding process. In Proceedings of the 22nd International ESAFORM Conference on Material Forming: ESAFORM 2019, Vitoria-Gasteiz, Spain, 8-10 May 2019; AIP Publishing: College Park, MD, USA, 2019; p. 40027.

15. Ambroziak, A.; Korzeniowski, M.; Kustroń, P.; Winnicki, M.; Sokołowski, P.; Harapińska, E. Friction Welding of Aluminium and Aluminium Alloys with Steel. Adv. Mater. Sci. Eng. 2014, 2014, 981653. [CrossRef]

16. Schuler, V.; Twrdek, J. Praxiswissen Schweißtechnik; Springer: Wiesbaden, Germany, 2019; ISBN 978-3-658-24265-7.

17. DIN Deutsches Institut für Normung E.V. DIN EN ISO 6507-1: Metallische Werkstoffe-Härteprüfung nach Vickers-Teil 1: Prüfverfahren (ISO 6507-1:2018); Deutsche Fassung EN ISO 6507-1:2018; Beuth Verlag GmbH: Berlin, Germany, 2018.

18. DIN Deutsches Institut für Normung E.V. DIN EN ISO 6892-1: Metallische Werkstoffe-Zugversuch-Teil 1: Prüfverfahren bei Raumtemperatur (ISO 6892-1:2016); Deutsche Fassung EN ISO 6892-1:2016; Beuth Verlag GmbH: Berlin, Germany, 2017.

19. Barienti, K.; Kahra, C.; Herbst, S.; Nürnberger, F.; Maier, H.J. Ion Beam Processing for Sample Preparation of Hybrid Materials with Strongly Differing Mechanical Properties. Metallogr. Microstruct. Anal. 2020, 9, 54-60. [CrossRef]

20. Liu, Y.; Zhao, H.; Peng, Y.; Ma, X. Microstructure and tensile strength of aluminum/stainless steel joint welded by inertia friction and continuous drive friction. Weld World 2020, 64, 1799-1809. [CrossRef]

21. Wang, T.; Sidhar, H.; Mishra, R.S.; Hovanski, Y.; Upadhyay, P.; Carlson, B. Evaluation of intermetallic compound layer at aluminum/steel interface joined by friction stir scribe technology. Mater. Des. 2019, 174, 107795. [CrossRef]

22. Eggeler, G.; Auer, W.; Kaesche, H. On the influence of silicon on the growth of the alloy layer during hot dip aluminizing. J. Mater. Sci. 1986, 21, 3348-3350. [CrossRef]

23. Cheng, W.-J.; Wang, C.-J. Effect of silicon on the formation of intermetallic phases in aluminide coating on mild steel. Intermetallics 2011, 19, 1455-1460. [CrossRef] 